\title{
Explanation of Tables
}

\author{
SIDE RUNNING HEADS
}

Cruise-identifying information is shown in the margin near the top of the page. The first line is an abbreviation of the name of the organization responsible for the data. The second and third lines give the cruise identification. In the case of data collected in the California Cooperative Oceanic Fisheries Investigations research program, for example, CCOFI 5901 signifies the January cruise of 1959.

Individual station numbers are given in the margin opposite the station data. The letter " $D$ " preceding the number indicates a drogue station; the letter " $\mathrm{K}$ " inserted in the station number denotes an anchor station. Raised numbers for the CCOFI stations indicate a position between lines or between stations of the standard station pattern. Station locations are shown in the appropriate position charts.

\section{HEADINGS OF GROUPS OF COLUMNS}

OBSERVED: Corrected data at accepted depths of observation.

INTERPOLATED: Data at standard depths, interpolated from smooth distribution curves or by machineinterpolation programs (see Notes on Particular Cruises). The standard depths are those selected by the agencies.

COMPUTED: The results of computations based, in general, on interpolated values.

\section{COLUMN HEADINGS}

Z Depth in meters at which observation was made or an interpolated value obtained.

T Temperature of water in degrees Celsius at observed or interpolated depths.

S Salinity of water in grams per kilogram (\%) at observed or interpolated depths.

$\mathrm{O}_{2} \quad$ Concentration of dissolved oxygen in milliliters per liter $(\mathrm{ml} / \mathrm{L})$ at observed or interpolated depths.

$\mathrm{PO}_{4}-\mathrm{P}$ Concentration of dissolved inorganic phosphorus in microgram atoms per liter ( $\mu \mathrm{g}$ at/L) or micromoles per liter at observed or interpolated depths.

$\mathrm{SiO}_{3}-\mathrm{Si}$ Concentration of dissolved silicon in microgram atoms per liter $(\mu \mathrm{g}$ at $/ \mathrm{L}$ ) or micromoles per liter at observed or interpolated depths.
$\mathrm{NO}_{2}-\mathrm{N}$ Concentration of dissolved inorganic nitrite nitrogen in microgram atoms per liter ( $\mu \mathrm{g}$ at/L) or micromoles per liter at observed depths.

$\mathrm{NO}_{3}-\mathrm{N}$ Concentration of dissolved inorganic nitrate nitrogen in microgram atoms per liter ( $\mu \mathrm{g}$ at $/ \mathrm{L}$ ) or micromoles per liter at observed depths.

$\sigma_{\mathrm{t}} \quad$ Sigma-t in grams per liter $(\mathrm{g} / \mathrm{L})$ at observed or interpolated depths. Sigma-t can be defined

$$
\sigma_{\mathrm{t}}=1000\left(\rho_{\mathrm{ST} 0}-1\right)
$$

where $\rho_{\mathrm{ST} 0}$ is the density, in grams per milliliter, of water of salinity, S, temperature, T, and at standard atmospheric pressure. Density is expressed in these units to be consistent with the tables used for the computations.

$\delta \quad$ Specific volume anomaly, in centiliters per ton (cl/ton), although most of the column headings state $10^{-5} \mathrm{~cm}^{3} / \mathrm{g}$. The difference between the two units is negligible in these data (Pollak, 1961), but the correct units are centiliters per ton (or $10^{-5} \mathrm{ml} / \mathrm{g}$ ). Specific volume anomaly is defined as the difference between the specific volume of the water at a specified depth and the specific volume of a standard water with salinity of $35 \%$ and temperature of $0^{\circ} \mathrm{C}$ at the same depth. Specific volume anomaly is expressed in these units to be consistent with the tables used for the computations.

$\delta_{\mathrm{T}} \quad$ Thermosteric anomaly, the pressure-independent part of the specific volume anomaly. Specific volume anomaly is defined

$$
\delta=\alpha_{\text {stp }}-\alpha_{35,0, p}
$$

and is computed as

$$
\delta=\Delta_{\mathrm{st}}+\delta_{\mathrm{sp}}+\delta_{\mathrm{tp}}
$$

The quantity $\Delta_{\text {st }}$ has been discussed by Sverdrup, Johnson and Fleming (1946, p. 58) and approximately represents potential specific volume anomaly. It is used here with the name (thermosteric anomaly), symbol $\left(\delta_{T}\right)$ and unit (centiliter per ton) suggested by Montgomery and Wooster (1954) although most of the column headings state $10^{-5} \mathrm{~cm}^{3} / \mathrm{g}$. The difference between the two units is negligible in these data (Pollak, 1961), but the correct units are centiliters per ton. 
Geopotential anomaly, in dynamic meters (dynamic height), of the layer of water between the surface and the designated standard pressure. Geopotential anomaly is the difference between the geopotential thickness of the observed layer and the geopotential thickness of a layer bounded by the same pressures but having standard temperature, $0^{\circ} \mathrm{C}$, and salinity, $35 \%$. The tabulated anomaly is determined from an approximation of the integral

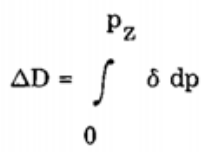

where $\mathrm{p}$ is pressure in decibars (assumed equal to depth in meters) and subscript $\underline{z}$ denotes the value at the bottom of the layer under consideration. Since geopotential thickness is the product of geometrical thickness and the acceleration of gravity, a dynamic meter is equal to $10^{5}$ ergs per gram and is the change in geopotential over a vertical distance of approximately 1.02 meter.

$\Delta D^{\prime}$

This quantity is calculated in a similar manner to $\Delta \mathrm{D}$ (see definition) except that it does not include the pressure terms $\delta_{\mathrm{sp}}$ and $\delta_{\text {tp }}$. It is equal to

$$
\Delta D^{\prime}=\int_{0}^{p_{z}} \delta_{T} d p
$$

\section{SUPPLEMENTARY STATION INFORMATION}

Supplementary information about each station is to be found just above the tabulated data. This information includes name of ship, data and time of observation, geographical location of station, depth of water, wind direction and force (usually Beaufort scale), a description of surface weather and sea state, and wire angle. When there is more than one cast on a station, messenger times and wire angles are given for the casts in the order of increasing depth.

\section{NOTES ON THE TABULATION OF DATA}

1. Observed temperatures obtained by thermograph, bucket thermometer or bathythermograph are reported only to tenths of a degree. Temperatures by reversing thermometer are reported to hundredths of a degree.

2. Observed salinities determined by the Knudsen method are reported to hundredths of a part per mille. Observed values determined by conductivity bridge are reported to thousandths of a part per mille.

3. Missing observed values are indicated by a hyphen $(-)$.

4. Extrapolated values and values interpolated between remote observations are entered within parentheses.

5. Observed data from different casts are separated by a blank line.

6. The following notations have been used where appropriate.

For premature or delayed closure of water bottle and reversal of thermometers:

$$
\text { p pretrip or posttrip }
$$

For values which are not used in interpolation because they seem to be in error:

$$
\mathrm{r} \text { rejected value }
$$

$\mathrm{u}$ uncertain value 